\title{
SHEAR-WAVE TRAVEL TIMES AND AMPLITUDES FOR TWO WELL- CONSTRAINED EARTHQUAKES
}

\author{
By Robert S. Hart and Rhett Butler
}

\begin{abstract}
The wave-form correlation technique (Hart, 1975) for determining precise teleseismic shear-wave travel times is extended to two large earthquakes with well-constrained source mechanisms, the 1968 Borrego Mountain, California earthquake and the 1973 Hawaii earthquake. A total of $87 \mathrm{SH}$ travel times in the distance range of $30^{\circ}$ to $92^{\circ}$ were obtained through analysis of WWSSN and Canadian Network seismograms from these two events. Major features of the travel-time data include a trend toward faster travel times at a distance of about $40^{\circ}$ (previously noted by lbrahim and Nuttli, 1967; Hart, 1975); another somewhat less pronounced trend toward faster times at about $75^{\circ} ;$ a +6 sec base line shift, with respect to the Jeffreys-Bullen Table, for the Borrego Mountain data; and large azimuthally-dependent scatter for the Hawaiian data, probably reflecting dramatic lateral variations in the near-source region. When azimuthal variations in the Hawaii data are removed, the travel times from both events show very low scatter. The correlations were also used to investigate $\mathbf{S H}$ amplitudes for possible distance dependence in the data and variations in $t_{\beta}{ }^{*}$. The Borrego Mountain data show very low scatter and no discernible distance dependence. All of the data are compatible with a value of $t_{\beta}{ }^{*}=5.2 \pm 0.5$. The amplitudes from the Hawail earthquake show the same azimuthal variations found in the travel-time data. When those effects are removed, the Hawaii data satisfies a value of $t_{\beta}{ }^{*}$ equal to $4.0 \pm 0.5$ and, as with the other data set, no distance dependence is apparent.
\end{abstract}

\section{INTRODUCTION}

The difficulty in determining the precise arrival times of teleseismic shear waves is a well-known problem in observational seismology. This difficulty arises largely from the fact that shear waves are secondary arrivals on the seismogram and the onset of the $S$-wave pulse is often obscured by precursory arrivals. This difficulty is further compounded by the relatively low $Q$ of most long-range $S$ waves. The high frequencies are thus preferentially removed from the pulse and the resulting arrival has a somewhat emergent onset. One promising approach was utilized by Hart (1975) to overcome these difficulties. This technique uses a wave-form correlation between the observed shear wave and a synthetic shear wave to obtain a reliable onset time of the observation. The success of the wave-form correlation method is directly dependent upon the accuracy with which the source time function is known for the event in question. At the time of the earlier study the seismic sources which best satisfied this requirement were nuclear explosions. Using a source derived in $P$ wave studies (Helmberger and Harkrider, 1972), and assuming the observed shear waves were generated as $p S$, Hart (1975) picked $S$ arrivals from five large nuclear explosions. However, the utility of explosion sources for shear-wave travel time studies is limited. Even the largest of the nuclear explosions produces only relatively low amplitude shear waves, making phase identification difficult. As the shear energy is theoretically pure $S V$, converted $P$ precursors and $P_{L}$ coupling contribute significantly to the noise. The considerable $S H$ energy observed from large explosions, and not predicted by the Helmberger-Harkrider model, may well be a further source of error. 
In this study we have adopted the wave-form correlation approach to pick $S H$ shear-wave arrival times from two large earthquakes, the 1968 Borrego Mountain and 1973 Hawaiian earthquakes. The source-time functions for both events have previously been carefully determined by body wave-form analysis (Burdick and Mellman, 1976; Butler, 1978a) and origin times and locations are well constrained due to local control. The degree to which local control constrains the origin time and hypocentral locations of these events is important, especially if we wish to compare baseline shifts. In the case of the Borrego Mountain earthquake, there is excellent control from the Caltech network. Allen and Nordquist (1972) estimated the epicenter location error to be within $3 \mathrm{~km}$. Their depth estimate of $11.1 \mathrm{~km}$ was confirmed by Burdick and Mellman (1976). With those limits, the effect of origin time and hypocenter errors on seismic travel times are bound by the instrument timing accuracy. In 1968, that accuracy was 0.4 to $0.5 \mathrm{sec}$ or better. Local control for the 1973 Hawaiian event is also good although not to the degree of the first event. The problem with the Hawaiian earthquake is that the epicenter lies just off the coast and thus slightly outside of the local seismic network. Since the depth can be fairly well constrained by the teleseismic wave-form analysis, the overall accuracy to which we can estimate origin effects on these travel-times is 1 to 2 sec. These errors, $\leqq 0.5 \mathrm{sec}$ for Borrego and $<2.0 \mathrm{sec}$ for Hawaii, can be considered as potential error limits on the travel-time base line for those events. The large $S H$ shear-wave energy generated by these events has allowed us to reliably pick travel times to distances of $90^{\circ}$. To avoid wave-form complications from upper mantle triplications, the minimum distance used was $30^{\circ}$. The amplitudes of $S$ waves from both these events were also examined for their implications on seismic $Q$ and upon regional mantle variations.

\section{Travel Times}

The first event used in this study was the Borrego Mountain, California earthquake. This event was a magnitude 6.4 strike-slip earthquake which occurred on April 9, 1968 at 02:28:59.1 GMT (Allen and Nordquist, 1972). The actual source mechanism of this earthquake was determined through a detailed inversion of teleseismic $P$ - and $S$-wave forms by Burdick and Mellman (1976). The Burdick and Mellman mechanism demonstrated that this earthquake was actually a multiple event consisting of a main shock and two aftershocks. The source parameters describing these three events are given in Table 1. Using the Burdick and Mellman mechanism it is a straightforward task to compute synthetic seismograms of the long-period $S$-wave arrivals. Since the Borrego Mountain earthquake was a shallow event, the observed $S$ pulse is actually a combination of both $S$ and $s S$ and the synthetics were constructed to include both rays. Figure 1 shows a comparison between the observed $S$ waves and synthetics for several stations. To include attenuation, the synthetics were convolved with a Futterman (1962) $Q$ operator with $t^{*}=5.2$, the value used by Burdick and Mellman (1976). Sirite the effect of errors in $t^{*}$ becomes more pronounced later in the wave form, to decermine the onset time of the observations, only the first swing of the $S$-wave pulse is used in the correlation procedure. This effectively reduces errors in the wave-form correlation method when the true attenuation is uncertain (Butler, 1977). It is possible not only to determine the best correlation and hence the best estimate of arrival time but also the total range of acceptable correlation. Thus, accurate estimates of error limits for the travel times were obtained. The Borrego Mountain data set yielded 42 highquality $S H$ arrivals on WWSSN and Canadian network stations in the distance 
range of $30^{\circ}$ to $92^{\circ}$. The travel times corresponding to these arrivals, corrected to the free surface and including elevation and ellipticity corrections, are listed in Table 2. In Figure 2 we have plotted 40 of these travel times as residuals with respect to the Jeffreys-Bullen (1940) Tables. The two stations deleted, KIP and

TABLE 1

Source Parameters for the Borrego Mountain and Hawait

EARTHQUAKES

Borrego Mountain

April 9, 1968; Lat. $=33.190^{\circ} \mathrm{N}$, Long. $=116.128^{\circ} \mathrm{W}$

Main shock: 02:28:59.1 GMT

Strike $=-45^{\circ}$, Dip $=81^{\circ}$, Rake $=178^{\circ}$, Depth $=8 \mathrm{~km}$

Moment $=11.2 \times 10^{25}$ dyne-cm

1st aftershock: 02:29:08.0 GMT

Strike $=128^{\circ}$, Dip $=77^{\circ}$, Rake $=12^{\circ}$, Depth $=7 \mathrm{~km}$

Moment $=2.46 \times 10^{25}$ dyne-cm

2nd aftershock: 02:29:14.4 GMT

Strike $=-91^{\circ}$, Dip $=28^{\circ}$, Rake $=98^{\circ}$, Depth $=11 \mathrm{~km}$

Moment $=0.78 \times 10^{25}$ dyne-cm

Hawaii

April 26,$1973 ;$ Lat $=19.903^{\circ} \mathrm{N}$, Long. $=155.130^{\circ} \mathrm{W}$

Main shock: 20:26:30.8 GMT

Strike $=-9^{\circ}$, Dip $=81^{\circ}$, Rake $=152^{\circ}$, Depth $=42 \mathrm{~km}$

Moment $=4.3 \times 10^{25}$ dyne-cm

1st aftershock: 20:26:34.0 GMT

Strike $=-14^{\circ}$, Dip $=94^{\circ}$, Rake $=145^{\circ}$, Depth $=32 \mathrm{~km}$

Moment $=1.3 \times 10^{25}$ dyne-cm

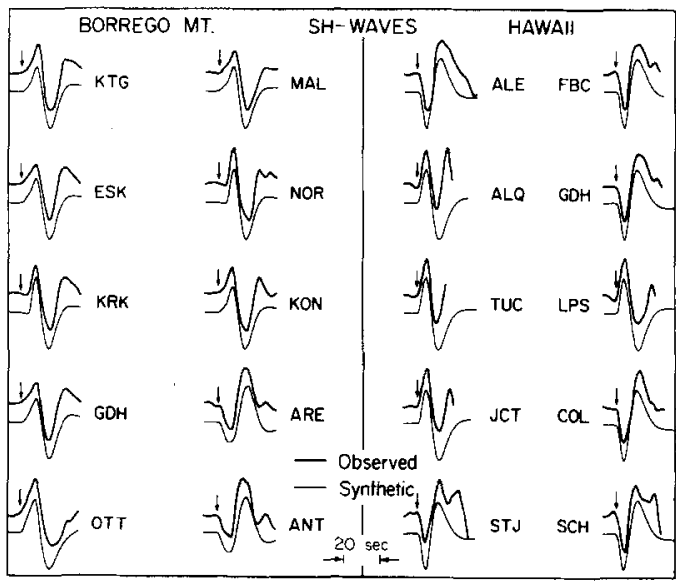

Frg. 1. Observed and synthetic $S H$ arrivals for 10 seismograms of the Borrego Mountain earthquake and 10 seismograms of the Hawaii earthquake. The Borrego Mountain synthetics include both the direct $S$ ray and the $s S$ arrival; the Hawaii synthetics, due to the large hypocentral depth of that event, include only the $S$ ray. The seismogram pairs are plotted with the synthetic trace beneath the observed trace. The predicted arrival time (best correlation time) of the $S H$ energy is indicated by a small arrow above each observed seismogram.

AKU, are tectonic island stations whose travel times are substantially late relative to other stations at the same distance range. An additional correction of $+0.4 \mathrm{sec}$ was given to stations with 30-90 instruments, (i.e., pendulum period of $30 \mathrm{sec}$ and galvanometer period of $90 \mathrm{sec}$ ), MNT, FBC, SCH, OTT, and RES. This correction equalizes the apparent onset time of a 30-90 instrument to that of a 15-100 instrument 
TABLE 2

SH Travel Times and Amplitudes from Borrego Mountain (Hypocenter corrected to surface)

\begin{tabular}{|c|c|c|c|c|c|c|}
\hline Sta. & $\begin{array}{c}\Delta \\
(\operatorname{deg})\end{array}$ & $\begin{array}{l}\text { Azimuth } \\
\text { (deg) }\end{array}$ & $\begin{array}{l}\text { T Obs. } \\
(\mathrm{m}: \mathrm{s})\end{array}$ & $\begin{array}{l}\text { Error } \\
\text { (sec) }\end{array}$ & $\begin{array}{l}T_{-T}-T_{j B} \\
\text { (sec) }\end{array}$ & $\begin{array}{c}\text { Amplitude } \\
\text { Ratio* }\end{array}$ \\
\hline SCB & 30.52 & 59.0 & $11: 21.8$ & $\begin{array}{l}+0.5 \\
-0.6\end{array}$ & 3.4 & 0.99 \\
\hline GEO & 31.91 & 68.4 & $11: 44.9$ & $\begin{array}{l}+0.4 \\
-0.5\end{array}$ & 4.7 & 0.76 \\
\hline SCP & 31.30 & 64.8 & $11: 33.5$ & $\begin{array}{l}+0.75 \\
-0.25\end{array}$ & 2.8 & 0.89 \\
\hline OGD & 33.76 & 64.4 & $12: 15.1$ & $\begin{array}{l}+0.5 \\
-0.5\end{array}$ & 6.0 & 0.98 \\
\hline OTT & 33.23 & 56.5 & $12: 04.8$ & $\begin{array}{l}+0.5 \\
-0.8\end{array}$ & 4.0 & 0.93 \\
\hline MNT & 34.71 & 56.6 & $12: 28.0$ & $\begin{array}{l}+0.5 \\
-0.8\end{array}$ & 4.3 & 0.97 \\
\hline WES & 36.22 & 62.1 & $12: 55.2$ & $\begin{array}{l}+0.7 \\
-0.5\end{array}$ & 8.1 & 1.09 \\
\hline SFA & 36.79 & 54.1 & $13: 00.2$ & $\begin{array}{l}+1.0 \\
-1.0\end{array}$ & 4.4 & 0.88 \\
\hline COL & 37.13 & 338.2 & 13:07.0 & $\begin{array}{l}+0.4 \\
-0.4\end{array}$ & 6.0 & - \\
\hline KIP & 38.79 & 263.9 & $13: 35.9$ & $\begin{array}{l}+0.9 \\
-0.5\end{array}$ & 9.2 & - \\
\hline $\mathrm{SCH}$ & 40.49 & 42.5 & $13: 55.8$ & $\begin{array}{l}+0.5 \\
-0.5\end{array}$ & 4.0 & 0.73 \\
\hline BHP & 41.44 & 117.2 & 14:09.8 & $\begin{array}{l}+0.5 \\
-0.5\end{array}$ & 4.4 & - \\
\hline MAL & 41.78 & 58.3 & $14: 15.8$ & $\begin{array}{l}+1.2 \\
-0.8\end{array}$ & 4.9 & 1.15 \\
\hline FBC & 42.33 & 29.2 & $14: 20.0$ & $\begin{array}{l}+1.0 \\
-1.0\end{array}$ & 0.9 & 0.73 \\
\hline RES & 42.86 & 8.1 & $14: 30.9$ & $\begin{array}{l}+1.0 \\
-1.0\end{array}$ & 4.1 & - \\
\hline BEC & 42.90 & 76.4 & $14: 31.7$ & $\begin{array}{l}+1.0 \\
-0.5\end{array}$ & 4.3 & 0.74 \\
\hline MBC & 43.16 & 358.9 & $14: 35.3$ & $\begin{array}{l}+0.5 \\
-0.6\end{array}$ & 4.1 & - \\
\hline QUI & 48.53 & 125.4 & $15: 56.4$ & $\begin{array}{l}+0.5 \\
-0.5\end{array}$ & 8.3 & 0.99 \\
\hline STJ & 49.06 & 53.3 & $16: 03.4$ & $\begin{array}{l}+0.3 \\
-0.3\end{array}$ & 7.9 & 1.28 \\
\hline $\mathrm{GDH}$ & 49.71 & 24.5 & $16: 11.8$ & $\begin{array}{l}+0.3 \\
-0.3\end{array}$ & 7.2 & 1.03 \\
\hline NNA & 58.49 & 133.4 & 18:09.7 & $\begin{array}{l}+0.5 \\
-0.8\end{array}$ & 6.7 & 0.76 \\
\hline NOR & 58.76 & 9.8 & $18: 11.8$ & $\begin{array}{l}+0.25 \\
-0.4\end{array}$ & 5.2 & - \\
\hline
\end{tabular}


SHEAR-WAVE TRAVEL TIMES AND AMPLITUDES FOR TWO EARTHQUAKES

TABLE 2-Continued

\begin{tabular}{|c|c|c|c|c|c|c|}
\hline Sta. & $\underset{\text { (deg) }}{\Delta}$ & $\begin{array}{l}\text { Azimuth } \\
\text { (deg) }\end{array}$ & $\begin{array}{l}\text { T Obs. } \\
\text { (m:s) }\end{array}$ & $\begin{array}{l}\text { Error } \\
\text { (sec) }\end{array}$ & $\begin{array}{l}\text { T-T. } \\
\text { (sec) }\end{array}$ & $\begin{array}{c}\text { Amplitude } \\
\text { Ratio* }\end{array}$ \\
\hline KTG & 60.49 & 22.7 & $18: 34.7$ & $\begin{array}{l}+0.7 \\
-0.25\end{array}$ & 5.8 & 1.19 \\
\hline AKU & 63.42 & 27.3 & $12: 15.2$ & $\begin{array}{l}+0.5 \\
-0.5\end{array}$ & 9.2 & 0.50 \\
\hline KBS & 64.24 & 9.7 & $19: 22.4$ & $\begin{array}{l}+0.25 \\
-0.3\end{array}$ & 6.2 & - \\
\hline ARE & 65.22 & 132.1 & 19:35.1 & $\begin{array}{l}+0.5 \\
-0.25\end{array}$ & 6.9 & 0.89 \\
\hline AFI & 70.77 & 238.1 & $20: 40.5$ & $\begin{array}{l}+1.0 \\
-0.5\end{array}$ & 5.9 & - \\
\hline ANT & 71.40 & 136.2 & $20: 49.2$ & $\begin{array}{l}+0.5 \\
-0.5\end{array}$ & 7.3 & 1.09 \\
\hline VAL & 73.39 & 38.4 & 21:38.4 & $\begin{array}{l}+0.5 \\
-0.6\end{array}$ & 4.2 & 0.84 \\
\hline KEV & 73.90 & 12.6 & $21: 13.9$ & $\begin{array}{l}+0.5 \\
-0.6\end{array}$ & 3.6 & 0.98 \\
\hline KRK & 74.47 & 11.6 & $21: 21.0$ & $\begin{array}{l}+0.5 \\
-0.7\end{array}$ & 4.3 & 1.06 \\
\hline ESK & 74.91 & 33.0 & $21: 26.3$ & $\begin{array}{l}+0.6 \\
-0.25\end{array}$ & 5.0 & 1.10 \\
\hline KON & 77.26 & 25.0 & $21: 54.5$ & $\begin{array}{l}+0.25 \\
-0.25\end{array}$ & 7.2 & 1.26 \\
\hline UME & 77.35 & 18.3 & $21: 53.2$ & $\begin{array}{l}+0.25 \\
-0.5\end{array}$ & 4.9 & 1.03 \\
\hline PEL & 78.63 & 142.4 & $22: 34.7$ & $\begin{array}{l}+0.25 \\
-0.7\end{array}$ & 5.2 & 0.96 \\
\hline PTO & 80.42 & 46.9 & $22: 06.8$ & $\begin{array}{l}+0.5 \\
-0.7\end{array}$ & 4.8 & 0.65 \\
\hline NUR & 81.25 & 18.5 & $22: 34.7$ & $\begin{array}{l}+0.25 \\
-0.7\end{array}$ & 5.2 & 1.43 \\
\hline LOR & 83.48 & 36.4 & $22: 58.8$ & $\begin{array}{l}+0.25 \\
-0.5\end{array}$ & 6.6 & 1.14 \\
\hline STU & 85.00 & 32.8 & $23: 15.1$ & $\begin{array}{l}+0.6 \\
-0.5\end{array}$ & 7.8 & 1.11 \\
\hline NAT & 85.35 & 99.1 & $23: 20.6$ & $\begin{array}{l}+0.7 \\
-0.25\end{array}$ & 9.9 & 0.92 \\
\hline MAL & 85.69 & 48.5 & $23: 18.9$ & $\begin{array}{l}+0.7 \\
-0.5\end{array}$ & 4.9 & 1.11 \\
\hline SHK & 86.72 & 309.6 & $23: 27.9$ & $\begin{array}{l}+0.5 \\
-0.5\end{array}$ & 4.0 & 0.87 \\
\hline LPA & 86.97 & 135.6 & $23: 30.0$ & $\begin{array}{l}+0.4 \\
-0.4\end{array}$ & 3.7 & 1.29 \\
\hline TRI & 89.36 & 36.2 & $23: 55.0$ & $\begin{array}{l}+0.7 \\
-0.5\end{array}$ & 6.4 & 1.12 \\
\hline $\mathrm{AQU}$ & 91.72 & 34.9 & 24:18.1 & $\begin{array}{l}+1.1 \\
-0.5\end{array}$ & 8.3 & 1.05 \\
\hline
\end{tabular}

* Synthetic amplitude computed assuming $M_{0}=1.00 \times 10^{26}$ dyne-cm, $t_{\beta}{ }^{*}=5.2$. 
(Butler, 1978b). The overall data set exhibits a +6 sec base line shift relative to the $\mathrm{J}-\mathrm{B}$ times. The structure between $35^{\circ}$ and $50^{\circ}$ appears consistent with earlier studies (Ibrahim and Nuttli, 1967; Hart, 1975). However, the residuals show a definite trough at about $75^{\circ}$ which has not previously been observed. Other significant features of these residuals are pronounced positive gradients with distance in the rang $\mathrm{s} 30^{\circ}$ to $35^{\circ}$ and $75^{\circ}$ to $92^{\circ}$. The first of these trends is in conflict with some earlier observations. However, rays at this distance range are bottoming just below

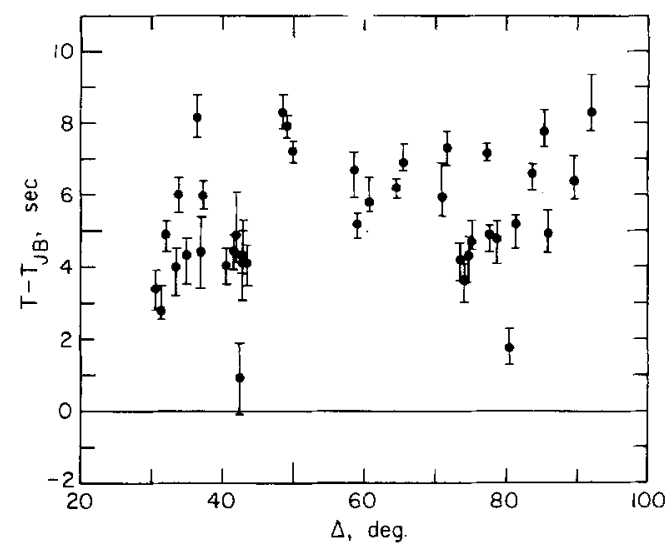

FIG. 2. $S H$ travel-time residuals with respect to the Jeffreys-Bullen Tables (1940) for the Borrego Mountain data set. The solid circle indicates the best correlation time. The error bars indicate the total range of acceptable correlation as well as estimates of reading and timing accuracies for each record.

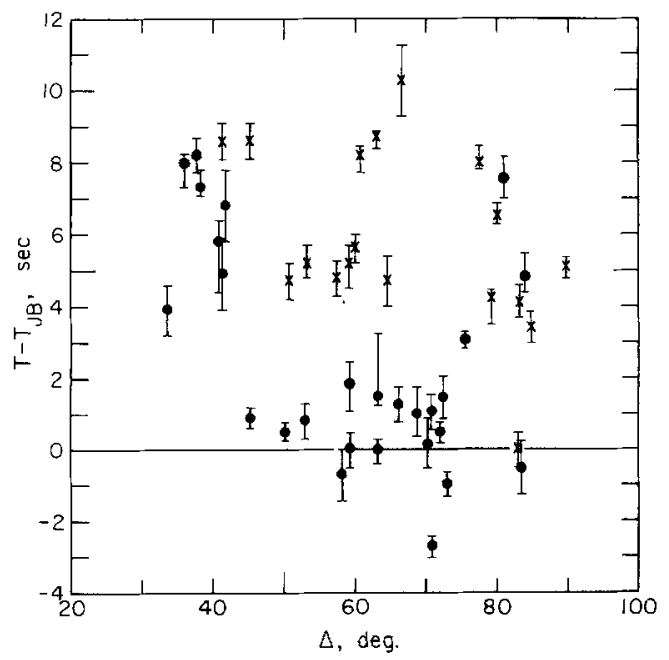

FIG. 3. $S H$ travel-time residuals with respect to the J-B Tables (1940) for the Hawaii data set. Those times plotted as solid circles correspond to stations whose azimuth from the source fall within the range of $0^{\circ}$ to $60^{\circ}$. All others are plotted as crosses.

the proposed $650 \mathrm{~km}$ discontinuity and regional variations in the depth and size of that discontinuity might be responsible for the travel-time differences.

The analysis of travel times from the Hawaiian earthquake is more complex. This event occurred on April 26, 1973 at 20:26:30.8 GMT northeast of the city of Hilo at a depth of $42 \mathrm{~km}$. The source mechanism of this earthquake (Butler, 1978a) is one of a double event with both shocks having similar mechanisms. Source parameters are given in Table 1. Synthetic shear waves were computed including only the direct $S$ wave from each shock as $s S$ comes in much later at these depths. To be consistent 
SHEAR-WAVE TRAVEL TIMES AND AMPLITUDES FOR TWO EARTHQUAKES 979

TABLE 3

Travel Times and Amplitudes from HawaiI

(Hypocenter corrected to $33 \mathrm{~km}$ depth)

\begin{tabular}{|c|c|c|c|c|c|c|c|}
\hline Sta. & $\begin{array}{c}\Delta \\
(\operatorname{deg})\end{array}$ & $\begin{array}{c}\text { Azimuth } \\
\text { (deg) }\end{array}$ & $\begin{array}{c}\text { T Obs. } \\
\text { (m:s) }\end{array}$ & $\begin{array}{c}\text { Error } \\
(\mathrm{sec})\end{array}$ & $\begin{array}{l}\mathrm{T}-\mathrm{T}_{\mathrm{JB}} \\
(\mathrm{sec})\end{array}$ & Amplitude $^{*}$ & Ratios $†$ \\
\hline BKS & 33.68 & 50.9 & 12:03.6 & $\begin{array}{l}+0.7 \\
-0.7\end{array}$ & 3.9 & 2.40 & - \\
\hline $\mathrm{COR}$ & 36.10 & 39.9 & $12: 45.1$ & $\begin{array}{l}+0.25 \\
-0.7\end{array}$ & 8.0 & 0.78 & 1.18 \\
\hline PHC & 37.73 & 24.0 & $13: 10.3$ & $\begin{array}{l}+0.5 \\
-0.5\end{array}$ & 8.2 & 0.79 & 1.20 \\
\hline VIC & 38.28 & 34.5 & $13: 17.8$ & $\begin{array}{l}+0.5 \\
-0.25\end{array}$ & 7.3 & 0.40 & 0.61 \\
\hline PNT & 40.79 & 35.7 & $13: 54.0$ & $\begin{array}{l}+0.6 \\
-1.4\end{array}$ & 5.8 & 0.56 & 0.85 \\
\hline DUG & 41.36 & 51.3 & $14: 01.5$ & $\begin{array}{l}+1.0 \\
-1.0\end{array}$ & 4.9 & 2.97 & - \\
\hline TUC. & 41.42 & 63.5 & $14: 06.1$ & $\begin{array}{l}+0.5 \\
-0.5\end{array}$ & 8.6 & 1.21 & - \\
\hline FSJ & 41.71 & 26.9 & $14: 08.6$ & $\begin{array}{l}+1.0 \\
-1.0\end{array}$ & 6.8 & 0.63 & 0.95 \\
\hline COL & 45.24 & 4.5 & $14: 54.0$ & $\begin{array}{l}+0.3 \\
-0.3\end{array}$ & 0.9 & 0.68 & 1.03 \\
\hline ALQ & 45.30 & 60.2 & $15: 02.6$ & $\begin{array}{l}+0.5 \\
-0.5\end{array}$ & 8.6 & 1.62 & - \\
\hline INK & 50.24 & 10.3 & $16: 04.1$ & $\begin{array}{l}+0.3 \\
-0.25\end{array}$ & 0.5 & 0.71 & 1.08 \\
\hline JCT & 50.73 & 66.5 & $16: 15.1$ & $\begin{array}{l}+0.5 \\
-0.5\end{array}$ & 4.7 & 1.37 & - \\
\hline FFC & 52.94 & 35.6 & $16: 41.5$ & $\begin{array}{l}+0.5 \\
-0.5\end{array}$ & 0.8 & 0.77 & 1.17 \\
\hline $\mathrm{DAL}$ & 53.25 & 63.4 & $16: 50.1$ & $\begin{array}{l}+0.5 \\
-0.4\end{array}$ & 5.2 & - & - \\
\hline GUA & 57.53 & 273.6 & $17: 46.8$ & $\begin{array}{l}+0.5 \\
-0.5\end{array}$ & 4.8 & 0.96 & - \\
\hline FCC & 58.25 & 32.5 & $17: 50.8$ & $\begin{array}{l}+0.7 \\
-0.7\end{array}$ & -0.7 & 0.87 & 1.32 \\
\hline MBC & 59.24 & 9.4 & 18:06.2 & $\begin{array}{l}+0.7 \\
-0.7\end{array}$ & 1.8 & 0.84 & 1.27 \\
\hline OXF & 59.31 & 61.1 & $18: 10.5$ & $\begin{array}{l}+0.5 \\
-0.7\end{array}$ & 5.2 & 1.03 & - \\
\hline LHC & 59.42 & 44.9 & $18: 06.7$ & $\begin{array}{l}+0.5 \\
-0.5\end{array}$ & 0.0 & 0.93 & 1.41 \\
\hline MAT & 59.94 & 301.3 & $18: 19.0$ & $\begin{array}{l}+0.4 \\
-0.4\end{array}$ & 5.6 & 1.79 & - \\
\hline SHA & 60.74 & 65.3 & $18: 31.9$ & $\begin{array}{l}+0.25 \\
-0.5\end{array}$ & 8.2 & - & - \\
\hline LPS & 62.97 & 83.7 & $18: 59.1$ & $\begin{array}{l}+0.2 \\
-0.3\end{array}$ & 8.7 & 1.06 & - \\
\hline AAM & 63.34 & 51.9 & $18: 56.5$ & $\begin{array}{l}+0.3 \\
-0.4\end{array}$ & 0.0 & - & - \\
\hline
\end{tabular}


TABLE 3-Continued

\begin{tabular}{|c|c|c|c|c|c|c|c|}
\hline Sta. & $\stackrel{\Delta}{\Delta}$ & $\begin{array}{c}\text { Azimuth } \\
\text { (deg) }\end{array}$ & $\begin{array}{l}\text { T Obs. } \\
\text { (m:s) }\end{array}$ & $\begin{array}{l}\text { Error } \\
\text { (sec) }\end{array}$ & $\begin{array}{l}\mathrm{T}-\mathrm{T}_{\mathrm{JB}} \\
(\mathrm{sec})\end{array}$ & Amplitude* & Ratios $\dagger$ \\
\hline SHK & 64.63 & 299.5 & 19:17.1 & $\begin{array}{l}+0.7 \\
-0.7\end{array}$ & 4.7 & 1.04 & - \\
\hline BLA & 66.30 & 57.2 & 19:34.1 & $\begin{array}{l}+0.5 \\
-0.5\end{array}$ & 1.3 & 2.94 & - \\
\hline GIE & 66.68 & 99.7 & $19: 47.7$ & $\begin{array}{l}+1.0 \\
-1.0\end{array}$ & 10.3 & 1.25 & - \\
\hline RES & 68.23 & 15.0 & $18: 56.6$ & $\begin{array}{l}+1.8 \\
-0.25\end{array}$ & 1.5 & 0.69 & 1.05 \\
\hline OTT & 68.78 & 48.0 & $20: 03.6$ & $\begin{array}{l}+0.8 \\
-0.6\end{array}$ & 1.0 & 0.53 & 0.80 \\
\hline $\mathrm{MNT}$ & 70.23 & 47.6 & $20: 19.8$ & $\begin{array}{l}+0.8 \\
-0.6\end{array}$ & 0.1 & - & - \\
\hline ALE & 70.76 & 8.0 & $20: 27.2$ & $\begin{array}{l}+0.5 \\
-0.5\end{array}$ & 1.1 & 0.65 & 0.98 \\
\hline FBC & 70.89 & 28.0 & $20: 24.6$ & $\begin{array}{l}+0.3 \\
-0.3\end{array}$ & -2.7 & 0.63 & 0.95 \\
\hline SFA & 71.88 & 45.6 & $20: 39.3$ & $\begin{array}{l}+0.3 \\
-0.3\end{array}$ & 0.5 & 0.60 & 0.91 \\
\hline WES & 72.40 & 50.6 & $20: 46.3$ & $\begin{array}{l}+0.6 \\
-0.6\end{array}$ & 1.5 & - & - \\
\hline $\mathrm{SCH}$ & 73.04 & 37.2 & $20: 51.0$ & $\begin{array}{l}+0.4 \\
-0.3\end{array}$ & -1.0 & 0.39 & 0.59 \\
\hline $\mathrm{GDH}$ & 75.59 & 21.1 & $22: 23.6$ & $\begin{array}{l}+0.25 \\
-0.25\end{array}$ & 3.1 & 0.62 & 0.94 \\
\hline QUI & 77.50 & 94.7 & $21: 49.3$ & $\begin{array}{l}+0.5 \\
-0.1\end{array}$ & 8.0 & 2.05 & - \\
\hline BAG & 79.33 & 283.6 & $22: 05.0$ & $\begin{array}{l}+0.3 \\
-0.7\end{array}$ & 4.2 & 0.45 & - \\
\hline $\mathrm{BOG}$ & 80.05 & 88.6 & $22: 14.8$ & $\begin{array}{l}+0.4 \\
-0.2\end{array}$ & 6.5 & 1.45 & - \\
\hline KBS & 81.11 & 2.5 & $22: 26.8$ & $\begin{array}{l}+0.7 \\
-0.5\end{array}$ & 7.5 & 0.47 & 0.71 \\
\hline SJG & 83.08 & 73.3 & 22:39.4 & $\begin{array}{l}+0.5 \\
-0.5\end{array}$ & 0.0 & 1.47 & - \\
\hline NNA & 83.28 & 105.2 & $22: 45.5$ & $\begin{array}{l}+0.5 \\
-0.4\end{array}$ & 4.1 & 0.88 & - \\
\hline STJ & 83.55 & 41.7 & $22: 43.6$ & $\begin{array}{l}+0.75 \\
-0.75\end{array}$ & -0.5 & 0.49 & 0.74 \\
\hline K'TG & 84.17 & 14.3 & $22: 55.1$ & $\begin{array}{l}+0.7 \\
-0.4\end{array}$ & 4.8 & 0.58 & 0.88 \\
\hline CAR & 84.82 & 80.7 & 23:00.1 & $\begin{array}{l}+0.5 \\
-0.4\end{array}$ & 3.4 & 2.38 & - \\
\hline ARE & 89.73 & 107.5 & $23: 48.3$ & $\begin{array}{l}+0.3 \\
-0.3\end{array}$ & 5.1 & 1.04 & - \\
\hline
\end{tabular}

* Synthetic amplitude computed assuming $M_{0}=8.0 \times 10^{25}$ dyne-cm; $t_{\beta}{ }^{2}=4.0$.

† Synthetic amplitude computed assuming $M_{0}=5.3 \times 10^{25}$ dyne-cm; $t_{\beta}{ }^{*}=4.0$. 
with the initial source study (Butler, 1978a), an attenuation operator with $t^{*}=4.0$ was used in the calculations. Figure 1 also illustrates several observed and synthetic $S$ waves for this event.

In Table 3 we have tabulated the corrected travel times for 45 observed $S H$ arrivals, spanning a distance range of $34^{\circ}$ to $90^{\circ}$. These travel times, plotted in Figure 3 as residuals with respect to $\mathrm{J}-\mathrm{B} 33-\mathrm{km}$ depth times, show large scatter. Much of the scatter, however, appears to be due to a rather pronounced laterally heterogeneous velocity structure at the source. In the wave-form analysis of the earthquake source Butler (1978a) found that shear waves passing under the island of Hawaii to stations in New Zealand, Australia, and New Guinea were far more complicated than comparable stations at other azimuths. Continuing on this tack we plot in Figure 4 location of the epicenter with respect to the Island of Hawaii and

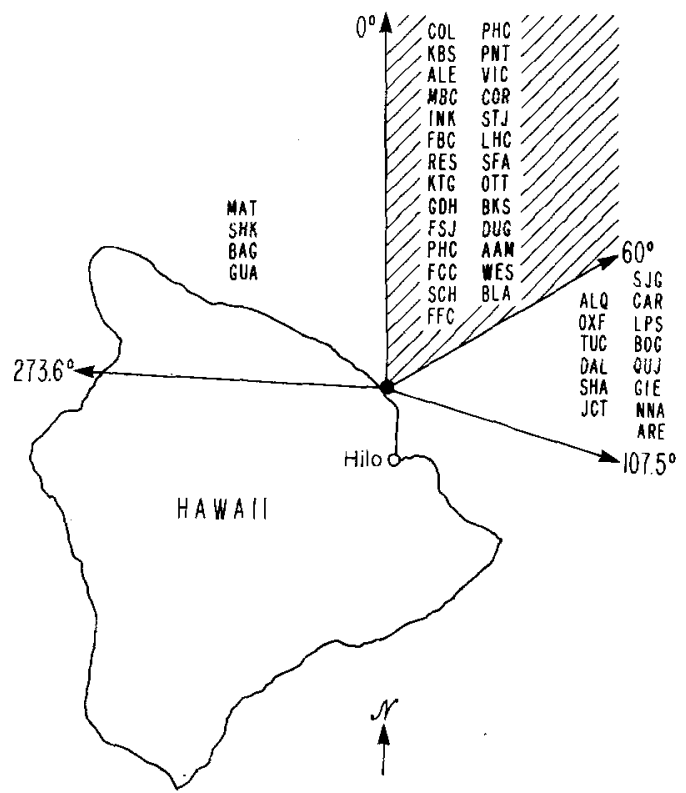

FIG. 4. Distribution, in azimuth, of WWSSN and Canadian Network stations used in the analysis of the Hawaiian earthquake. Stations outside the shaded regions show anomalous travel times and amplitudes.

the azimuthal window of station coverage. Travel-time residuals at stations at azimuths within the shaded wedge are plotted as circles in Figure 3, those outside this wedge as crosses. In Figure 5, we have plotted these residuals as a function of azimuth from the epicenter for those stations with azimuths between $0^{\circ}$ and $107.5^{\circ}$ and distances between $42^{\circ}$ and $80^{\circ}$ to further clarify this point. The much lower scatter exhibited in the travel times of rays leaving the island to the northeast compared to rays at other azimuths strongly suggests a sharply varying velocity structure on the edges of the island of Hawaii. This change cannot be presumed to reflect differences in tectonic settings of the stations. From Figure 4 we see that roughly half of the stations leaving with azimuths greater than $60^{\circ}$ are mid-Continental North America. There is no obvious reason, for example, to expect travel times to these stations to differ markedly from those at other stations, (e.g., AAM or BLA) located in the area. In the further consideration of the travel times from the Hawaiian earthquake we shall consider only the "circle" stations. Beyond a 
distance of $45^{\circ}$, the times have a base line quite close to $\mathrm{J}-\mathrm{B}$ and show no strong trend. The residuals for distances less than $45^{\circ}$, which represent stations on the west coast of North America, are much greater.

\section{AMPLITUDES}

The amplitudes of $S H$ waves from both events were measured in order to investigate possible distance dependence in the data sets and variations in $t_{\beta}{ }^{*}$. In

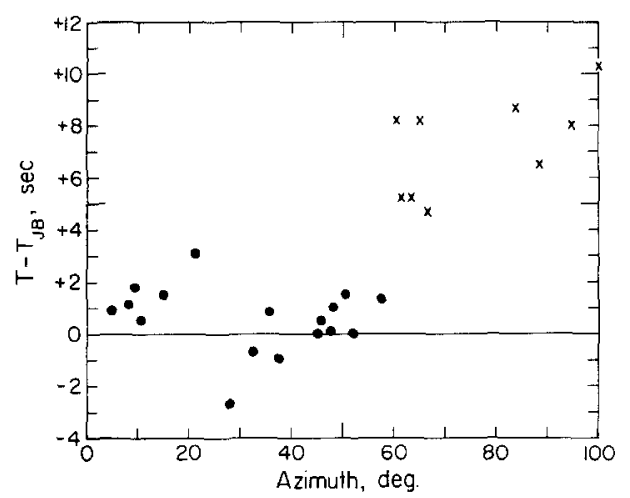

FIG. 5. SH travel-time residuals from Hawaii, with respect to the J-B tables (1940) as a function of azimuth from the epicenter for stations in the distance range $42^{\circ}$. to $80^{\circ}$ and azimuths between $0^{\circ}$ and $107.5^{\circ}$.

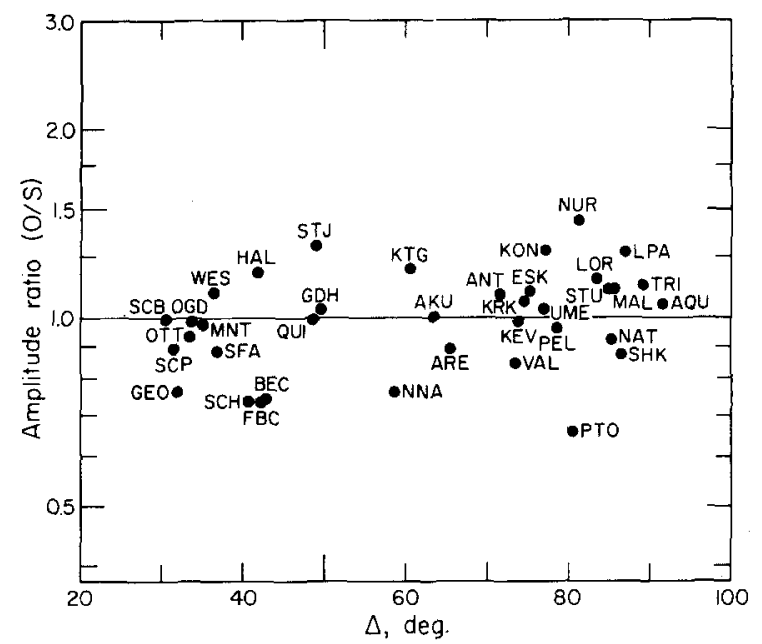

FIG. 6. $S H$ amplitude ratios (observed/synthetic) for the Borrego Mountain earthquake as a function of distance assuming a moment of $1.0 \times 10^{26}$ dyne-cm and a value for $t_{\beta}{ }^{*}$ of 5.2 .

order to minimize errors resulting from $P$-wave contamination when rotating the observations, only records that were strongly $S H$ were used. This reduces both data sets to 37 stations for the Borrego Mountain earthquake and 39 stations for the Hawaiian event. Synthetic shear waves calculated for these stations were corrected for geometric spreading assuming a Jeffreys-Bullen model.

In Figure 6 we have plotted the ratio of the observed amplitude to the synthetic amplitude for the shear waves from Borrego (the amplitude ratios are also listed in Table 2). In computing the synthetic amplitudes we have used a value of $1.0 \times 10^{26}$ dyne-cm for the earthquake moment. This value is consistent with the $1.12 \times 10^{26}$ dyne-cm determined by Burdick and Mellman (1976) using both $P$ - and $S$-wave 
amplitudes. The $t_{\beta}{ }^{*}$ value of 5.2 determined by Burdick and Mellman was also used here. In general, the amplitudes show very little scatter with no significant distance dependence. All of the amplitudes can be fit by assuming no more than a \pm 0.5 variation in $t_{\beta}{ }^{*}$. Comparison with the travel-time residuals reveals no consistent correlations although it is rather curious PTO is both fast and more highly attenuated and WES and KON are both slow and rather less attenuated than other stations at the same distance ranges.

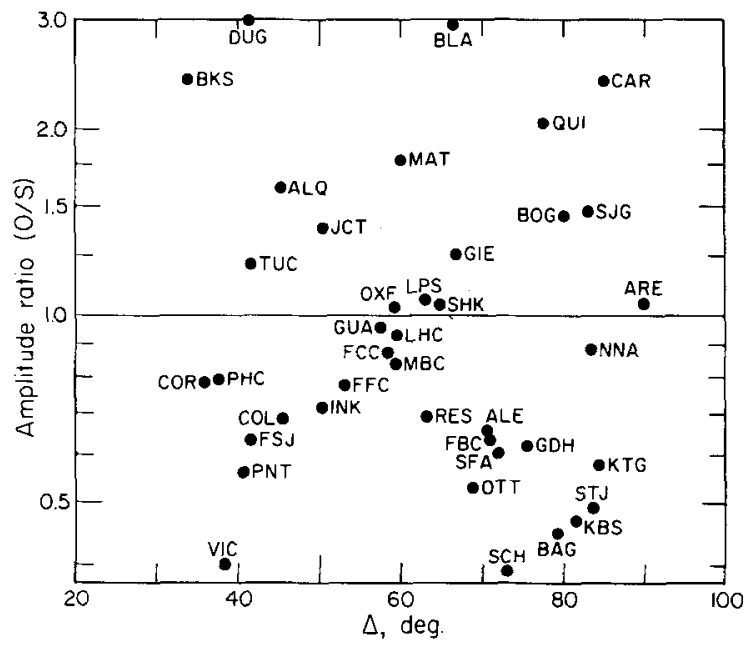

FIG. 7. $S H$ amplitude ratios as a function of distance for the complete Hawaiian earthquake data set assuming a moment of $8.0 \times 10^{25}$ dyne-cm and a $t_{\beta}{ }^{*}=4.0$.

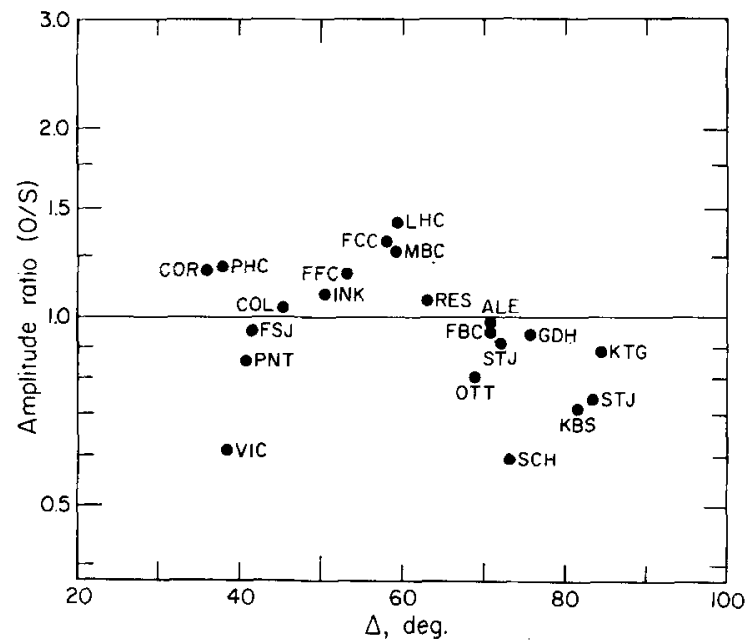

FIG. 8. $S H$ amplitude ratios as a function of distance for the reduced Hawaiian earthquake data set (i.e., only those stations at azimuths between $0^{\circ}$ and $60^{\circ}$ ), assuming a moment of $5.3 \times 10^{25}$ dyne-cm and $t_{\beta}{ }^{*}=4.0$.

The amplitude analysis for the Hawaii earthquake $S$ waves is less simple, as was the case for the travel times. The amplitude ratios for this event are plotted in Figure 7 assuming a moment of $8.0 \times 10^{25}$ dyne-cm and a $t_{\beta}{ }^{*}$ value of 4.0 . These ratio values are also tabulated in Table 3 . As the scatter in the amplitude ratios is very large, it is interesting to examine the data for an azimuthal dependence similar to that present in the travel-time data. If we consider only stations with azimuths that fall within the shaded wedge in Figure 3 , the scatter is considerably reduced as 
these stations all lie in the lower part of Figure 6. This new data set, plotted in Figure 8 with a revised moment of $5.3 \times 10^{25}$ dyne-cm, shows no persuasive distance dependence or correlation with travel time. As with the Borrego Mountain data this amplitude scatter may be explained with a variation of $t_{\beta}{ }^{*}$ of $\pm 0.5 \mathrm{sec}$.

\section{Discussion}

The Borrego Mountain data set has no internal azimuthal variations, but exhibits a 6 -sec base line shift relative to J-B. $P$-wave residuals for stations of the Caltech Seismic Network in the vicinity of the Borrego Mountain epicenter tend to cluster at about $+0.6 \pm 0.5 \mathrm{sec}$ relative to $\mathrm{J}-\mathrm{B}$ (Raikes, personal communication). The origin time of the earthquake determined by the ISC is $1.1 \pm 0.2 \mathrm{sec}$ later than the well constrained Caltech determination. The ratio of $S$-wave station anomaly to $P$-wave anomaly has been found by many workers to be on the order of 4 (Doyle and Hales, 1967; Hales and Roberts, 1970; Followill and Nuttli, 1970). Thus about 4 sec of the Borrego $S$-wave base line may be consistent with observed station anomalies. The Borrego Mountain epicenter is located within the proximity of the landward extension of the Gulf of California ridge system. These extraordinarily slow $S$ times are evidence of some process which slows shear waves more than compressional waves. A zone of partial melt beneath the area could qualitatively fulfill this requirement. In addition, since the epicenter lies on the western side of California's Imperial Valley, a highly tectonic region, it is particularly interesting that no azimuthal variation is apparent in travel times or amplitudes.

The Borrego Mountain data exhibit a distinct trough in the trend of J-B residuals at a distance of $75^{\circ}$ which has not previously been reported. The coverage in the Hawaiian data at this range is insufficient to resolve this. The bottoming depth of these rays is approximately $2000 \mathrm{~km}$.

The amplitudes for the Borrego and the corrected Hawaiian data show no significant distance dependence. The overall scatter in the amplitudes can be explained with variations in $t_{\beta}{ }^{*}$ of the order of \pm 0.5 sec. More data, however, are required to determine the systematics of station amplitudes more quantitatively.

\section{ACKNOWLEDGMENTS}

The authors thank David Hadley for critically reading the manuscript. This research was supported by the Advanced Research Projects Agency of the Department of Defense and was monitored by the Air Force Office of Scientific Research under Contract F49620-77-C-0022. Rhett Butler was supported by a Fannie and John Hertz Foundation Fellowship.

\section{REFERENCES}

Allen, C. R. and J. M. Nordquist (1972). Foreshock, main shock and larger aftershocks of the Borrego Mountain earthquake, U.S. Geol. Survey Profess. Paper 787, 16-23.

Burdick, L. J. and G. R. Mellman (1976). Inversion of the body waves from the Borrego Mountain earthquake to the source mechanism, Bull. Seism. Soc. Am. 66, 1485-1499.

Butler, R. (1977). A source of bias in multiple ScS differential times determined by waveform correlation, Geophys. Res. Letters, 4, 593-596.

Butler, R. (1978a). Body wave analysis of the April 26, 1973, Hawaiian earthquake (submitted for publication).

Butler, R. (1978b). Instrumental delay in the measurement of travel times for various transient seismic pulses (submitted for publication).

Doyle, H. A. and A. L. Hales (1967). An analysis of the travel times of $S$ waves to North American stations in the distance range of $28^{\circ}$ to $82^{\circ}$, Bull. Seism. Soc. Am. 57, 761-771.

Followill, F. E. and O. W. Nuttli (1970). Shear body wave travel times and velocity distribution in the lower mantle (abstract), Geol. Soc. Am., 66th Annual Mtg. 2, 92.

Futterman, W. I. (1962). Dispersive body waves, J. Geophys. Res. 67, 5279-5291. 
SHEAR-WAVE TRAVEL TIMES AND AMPLITUDES FOR TWO EARTHQUAKES 985

Hales, A. L. and J. L. Roberts (1970). Shear velocities in the lower mantle and the radius of the core, Bull. Seism. Soc. Am. 60, 1427-1436.

Hart, R. S. (1975). Shear velocity in the lower mantle from explosion data, J. Geophys. Res. 80, $4889-4894$.

Helmberger, D. V. and D. G. Harkrider (1972). Seismic source descriptions of underground explosions and a depth discriminate, Geophs. J. 31, 45-66.

Ibrahim, A. K. and O. W. Nuttli (1967). Travel-time curves and upper mantle structure from long period $S$ waves, Bull. Seism. Soc. Am. 57, 1063-1092.

Jeffreys, H. and K. E. Bullen (1940). Seismological Tables, Brit. Assoc. Advan. Sci., Gray-Milne Trust, London, $55 \mathrm{pp}$.

SEISMOLOGICAL LABORATORY

Division of Geological and Planetary SCIENCES

California Institute of TechNology

Pasadena, California 91125

Contribution No. 2999

Manuscript received November 18, 1977 